\title{
Representações Sociais do espaço urbano turístico de Ilhéus, Bahia (Brasil), na perspectiva do residente
}

\section{Social Representations of the urban touristic space in Ilhéus, Bahia (Brazil), from the perspective of the resident}

\author{
Charles dos Reis Alves (ALVES, C. dos R.) ${ }^{*}$, \\ Luciana Luísa Chaves Castro (Castro, L. L. C.) ${ }^{* *} \mathrm{e}$ \\ Natanael Reis Bomfim (BOMFIM, N. R.)
}

\begin{abstract}
RESUMO - Objetiva-se compreender a representação social do espaço urbano turístico da cidade de Ilhéus, Bahia (Brasil), a partir de fotografias tomadas por residentes. Para tanto, faz-se uma abordagem teórica sobre espaço urbano, cidade e espaço urbano turístico, aliada a Teoria das Representações Sociais proposta por Moscovici (2003). Metodologicamente, utilizou-se a análise de conteúdo das fotografias tomadas pelos atores sociais, bem como dados bibliográficos. Foram adotadas as categorias de análise das representações sociais, bem como as divisões dos elementos do espaço urbano turístico descrito por Boullón (2002). Assim, evidenciou-se como as Representações Sociais se constituem numa ferramenta capaz de auxiliar no entendimento da representatividade do espaço para os diversos atores sociais envolvidos na construção simbólica e real deste.
\end{abstract}

Palavras-chave: Espaço Urbano; Turismo; Representação Social; Fotografia; Ilhéus.

ABSTRACT - This paper aims to understand the social representation of urban touristic space in Ilhés, Bahia (Brazil), using pictures taken by residents. Therefore it was done a theoretical approach about urban space, cities and urban touristic space associated with the social representations theory proposed by Moscovici (2003). Methodologically, it was done an analysis of pictures contents taken by social actors, as well as bibliographic data. It was adopted the analysis categories of social representations, as well as the divisions of the elements of urban tourist space described by Boullon (2002). Thus, it was pointed how the social representations could be a tool to help understanding the representation of the space for various social actors involved on the symbolic and real construction of that space.

Key words: Urban Space; Tourism; Social Representation; Photography (pictures); Ilhéus.

\footnotetext{
* Graduação em Comunicação Social e Mestrando em Cultura e Turismo pela Universidade Estadual de Santa Cruz (UESC), Ilhéus, Bahia. Analista de Comunicação da Agência Goiana de Comunicação Produtor Executivo da TV Brasil Central. Endereço: Universidade Estadual de Santa Cruz, Campus Soane Nazaré de Andrade, km 16, Rodovia Ilhéus-Itabuna. CEP 45662-900 - Ilhéus - Bahia (Brasil). Telefone: (62) 8199-9229. E-mail: charles_reis_alves@ hotmail.com

** Graduação em Turismo pela Universidade Federal do Maranhão (UFMA). Mestranda em Cultura e Turismo pela Universidade Estadual de Santa Cruz (UESC), Ilhéus, Bahia. Endereço: Universidade Estadual de Santa Cruz, Campus Soane Nazaré de Andrade, km 16, Rodovia Ilhéus-Itabuna. CEP 45662900 - Ilhéus - Bahia (Brasil). Telefones: (73) 91566215/(98) 88257827. E-mail: llccturismo@yahoo.com

*** Graduação em Geografia pela Universidade Católica do Salvador (UCSal). Mestrado em Educação pela Universidade Federal da Bahia (UFBA). Doutorado em Educação pela Universidade do Quebec em Montreal. Professor Titular da Universidade Estadual de Santa Cruz (UESC), Ilhéus, Bahia, atuando na Graduação em Geografia e no Mestrado em Cultura e Turismo. Endereço: Universidade Estadual de Santa Cruz, Campus Soane Nazaré de Andrade, km 16, Rodovia Ilhéus-Itabuna. CEP 45662-900 - Ilhéus - Bahia (Brasil). Telefone: (73) 3680-5141. E-mail: nabom@ hotmail.com
} 


\section{INTRODUÇÃO}

O espaço urbano constitui um importante local para estudos, pois é nesse ambiente que ocorrem as mais diversas formas de manifestações, sejam políticas, culturais ou sociais. $\mathrm{O}$ espaço urbano revela traços das organizações sociais e, igualmente, evidencia a maneira como isso ocorre. Nele as pessoas criam estruturas, agem sobre a natureza, modificam e constroem paisagens, confrontando e sendo constantemente confrontadas pelo espaço.

Nessa visão epistemológica, o espaço urbano surge do movimento dinâmico e contínuo de produção e reprodução, onde o espaço urbano real e o simbólico caminham juntos à medida que o indivíduo atribui valores e significados ao primeiro. O espaço urbano é fonte de significados, revelando variadas representações sociais. Nesse sentido, a imagem material reflete as subjetividades, podendo-se dizer que as fotografias materializam e refletem a subjetividade dos sujeitos em relação ao espaço real urbano.

No turismo, o espaço urbano ganha destaque por ser um ambiente de descobertas e, portanto, áreas a serem fruídas e compreendidas pelos turistas, considerando as construções simbólicas geradas pelo lugar, incluindo a história, as belezas naturais, os valores sociais e a identidade cultural do local.

A cidade de Ilhéus, Bahia (Brasil), como espaço urbano turístico, expressa essa materialidade através de características naturais, culturais e históricas surgidas ao longo do tempo, decorrentes do contexto social e de representações simbólicas dos residentes. Dentro da configuração do desenvolvimento do turismo no Estado da Bahia, a cidade integra a Costa do Cacau, assim denominada referenciando o cultivo do cacau, fruto que possibilitou não apenas o avanço econômico, como também a construção de imaginários a respeito da sociedade local.

Como potenciais naturais, Ilhéus possui diversos rios e $83 \mathrm{~km}$ de praias. Sua fauna e flora são reveladas pela Mata Atlântica. As características históricas e culturais estão alicerçadas em traços da colonização no período em que o município foi sede das Capitanias Hereditárias de Portugal, bem como às do auge da lavoura cacaueira. A arquitetura expressa casarões, ruas, igrejas, marcos antigos ao passo que comporta novos modelos de urbanização. As manifestações culturais e religiosas possuem fortes 
influências dos povos negros, brancos e índios. As lutas por terra e hierarquias de poder percorrem o imaginário social nas obras de autores como Adonias Filho e Jorge Amado.

Perante as características do espaço urbano, a cidade de Ilhéus agrega qualidades que a tornam um local com potencial turístico. A esse respeito é importante mencionar que a atividade turística revela uma dinâmica que provoca transformações no espaço, a partir do momento em que uma localidade passa a alocar investimentos e ampliar a sua infraestrutura urbana, bem como a estruturar produtos e serviços visando satisfazer as necessidades e expectativas dos visitantes. Contudo, partindo do pressuposto de Bomfim (2009) de que o vendedor dos produtos turísticos é também o principal consumidor, o residente, é preciso atentar para as representações sociais que tais sujeitos têm para com o espaço urbano turístico, a fim de entender as relações sociais estabelecidas e os valores atribuídos aos seus espaços de vivência.

Diante disso, o estudo objetivou analisar a representação social do espaço urbano turístico a partir de fotografias feitas pelos residentes da cidade. Trata-se de pesquisa qualitativa e interpretativa. Para tanto, faz-se uma abordagem teórica sobre espaço urbano, cidade e espaço urbano turístico e utiliza-se da Teoria das Representações Sociais para perceber os significados embutidos nas imagens cristalizadas. A área estudada compreende à de lugares turísticos dentro dos roteiros ordenados de Ilhéus.

A coleta de dados primários foi efetivada a partir de uma amostragem nãoprobabilística por julgamento, tendo como amostra 4 residentes de Ilhéus. Utilizou-se o registro fotográfico do espaço urbano turístico da cidade a partir de fotografias feitas pelos moradores, sendo 2 fotos de elementos que gostassem e 2 fotos de elementos que não gostassem. Destaca-se que para a captura das imagens fotográficas não se impôs nenhuma restrição ou exigência a respeito da qualidade técnica e estética das imagens, de modo que o residente fizesse o registro da forma que melhor lhe conviesse.

Como resultado dos registros fotográficos tem-se 16 fotografias dos lugares turísticos de Ilhéus, constituindo o objeto social de análise do estudo. Por se tratar de um estudo preliminar, de caráter qualitativo e interpretativo, considera-se a amostra de 4 residentes como relevante para alcançar o objetivo proposto no trabalho, que é de analisar a representação do espaço urbano para determinados moradores da cidade, interessando-se em perceber o que se torna latente nas fotografias feitas por estes. 
Contudo, ressalta-se a importância de em outro momento de pesquisa aumentar o número da amostra para discussões mais aprofundadas e abrangentes.

A análise partiu da Teoria das Representações Sociais, considerando-a uma importante base teórico-metodológica para compreender as categorias de crenças, valores, mitos, preconceitos, atitudes e estereótipos embutidos e manifestados nos comportamentos dos residentes. Como variáveis têm-se os elementos dos espaços urbanos turísticos descritos por Boullón (2002), sendo logradouros, bairros, bordas, marcos, setores e roteiros cristalizados nas imagens fotográficas.

\section{REPRESENTAÇÕES SOCIAIS RELACIONADAS AO ESPAÇO URBANO}

A materialização do espaço urbano reflete as relações sociais estabelecidas nesse tipo de ambiente. O turismo, aliado ao espaço urbano, converte-se em agente responsável tanto pela produção quanto transformação deste, uma vez que gesta esse espaço de acordo com as potencialidades de cada local.

Nos apontamentos de Siviero (2006), consta que o desenvolvimento da atividade turística está integrado ao contexto do espaço, considerando que os atrativos, os equipamentos e a infraestrutura surgem de forma física e visível neste ambiente, sobretudo no espaço urbano. A cidade aparece como fruto e materialização das relações sociais. O espaço urbano seria o conteúdo das relações sociais mantidas pelos indivíduos.

A conectividade entre cidade e espaço urbano permite identificar as influências de um em relação ao outro, manifestadas na dinâmica das relações sociais estabelecidas e que totalizam um conjunto de representações simbólicas construídas ao longo do espaço e do tempo. Essas representações são produzidas no passado e no presente, evidenciando sinais da organização espacial, gerando as crenças, valores e mitos, muitas vezes expressos na produção de formas espaciais como, por exemplo, monumentos, marcos, lugares sagrados (SIVIERO, 2006).

Boullón (2002) estabelece uma classificação dessas formas espaciais, dividindo o espaço urbano turístico a partir das seguintes estruturas: bairros, setores, bordas, logradouros, marcos e roteiros. Os bairros como seções relativamente grandes nas 
cidades, onde o turista pode deslocar-se para conhecer diversos atrativos. Já os setores como partes menores do espaço urbano, sendo, geralmente, vestígios de bairros antigos que foram englobados por outras estruturas modernas. As bordas como elementos que demarcam as fronteiras entre duas partes de uma cidade. Organizadas linearmente, elas rompem a continuidade homogênea do espaço e definem os pontos extremos, podendo ser fortes (rios, ferrovias, estradas) ou fracas (avenidas, ruas com dimensões distintas, edificações com alturas diferentes ou mesmo estilos arquitetônicos distintos, evidenciando passagens de tempo).

Para o autor, os logradouros são espaços abertos ou não, onde os residentes e turistas podem entrar e percorrer livremente, como por exemplo, praças, feiras, galerias, zoológicos. Os marcos como equivalentes a monumentos, praças, fontes, grandes construções, ou mesmo cartazes que, por suas dimensões e formas, destacam-se como pontos referenciais. E, finalmente, os roteiros se caracterizando por serem vias por onde se deslocam os pedestres e turistas para visitação dos atrativos turísticos.

Como se constata o ordenamento do espaço urbano é fonte de grandes significados, expressos no seu patrimônio material e imaterial. Dessa maneira, o espaço urbano turístico nada mais seria do que a apropriação de alguns espaços urbanos para o desenvolvimento da atividade turística. Ou seja, é pelo processo de consumo do espaço pelo turismo que nascem os espaços turísticos.

Assim exposto, é importante pensar que o espaço urbano turístico não é expresso apenas em materializações, mas também em produções simbólicas evidenciadas nesses lugares, carregadas de significações e representações. Apreender essas representações sociais, culturais e simbólicas é fundamental para compreender e interpretar os lugares turísticos, bem como regular as relações entre o turismo e a comunidade, permitindo, ainda, avaliar as práticas sociais por meio de atitudes e valores conferidos ao espaço de vivência, viabilizando o planejamento sustentável do turismo (BOMFIM, 2009).

Os lugares são valorizados pelos seus atributos físicos e simbólicos, refletindo as suas práticas sociais. A conclusão é que o espaço é objeto de representação, sendo ao mesmo tempo espaço físico e de vivência, referenciando tanto as representações mentais quanto o produto traduzido em imagens estruturadas entre o que é de ordem simbólica e real. Para complementar o entendimento dessa relação, é pertinente reportar-se aos estudos de Castrogiovanni (2001), onde são apresentados alguns 
componentes da paisagem urbana, tais como: forma, identidade, função, estrutura, processo e significado.

A forma implica nos aspectos exteriores e visíveis que compõem a cidade. A identidade é associada às singularidades, aos significados atribuídos no campo material ou emocional. Já a função diz respeito ao papel cotidiano desempenhado pelos espaços urbanos, não existindo uma função fixa, o que aproxima essa categoria das representações sociais que são passíveis de mudanças. A estrutura relaciona-se com a natureza social, histórica e às questões econômicas na formação da sociedade, sendo a matriz em que as formas e funções sociais são criadas. O processo é o conjunto de ações contínuas que visam obter resultados de interesses dos atores urbanos e implicam mudanças no tempo.

Pode-se dizer que o espaço urbano, e especificamente o espaço urbano turístico, é fonte de grandes significados, tanto para os moradores quanto para os turistas. Mas, como ressalta Siviero (2006), essa relação é dinâmica, pois um equipamento do espaço urbano pode ser atrativo para o turista e não significar nada, ou quase nada, para os residentes e vice-versa. Essa dedução é possível quando se entende que o espaço urbano é carregado de representações. Nessa perspectiva, a Teoria das Representações Sociais de Moscovici (2003) vem colaborar para o entendimento dessa complexidade.

A partir das Representações Sociais é possível entender como ocorre o processo de familiarização e de atribuição de significados dos sujeitos para com o universo que os rodeia. O princípio de Moscovici (2003) é que a principal finalidade das representações é tornar familiar o não-familiar. As representações orientam as pessoas em direção ao que é visível, ao que tem que ser respondido, ou seja, as representações correspondem ao que o sistema perceptivo e cognitivo está ajustado. Isso ocorre porque as representações convencionam os objetos, as pessoas e os acontecimentos. Elas são prescritivas, se impõem sem que necessariamente se tenha consciência disso.

As construções das representações sociais, que ocorrem por meio das interações sociais e que são difundidas em grande escala por meio da comunicação, são absorvidas pelas pessoas e passam a pertencer ao senso comum. Ideologias são incorporadas a essas representações, atribuindo outros valores, guiando os comportamentos em relação aos objetos representados. As representações sociais são a base para produção de conhecimento que dificilmente é destruída, porém está em constante transformação. 
Elas estão ligadas à produção de sentido, de opinião e de imagens mentais sobre os objetos que permeiam o mundo dos indivíduos. Percebe-se que a representação social é um fenômeno dinâmico, simbólico e prático, que está relacionado a produção de sentido.

As representações sociais ligam-se às histórias e a cultura de cada indivíduo, estando no contexto das vivências e experiências. Elas estão na base das identidades, isso significa afirmar que desconstruir ou interferir nas representações implica na mudança de uma percepção sobre o mundo e, consequentemente, transformações na identidade.

Para Moscovici (2003, p. 54) as representações sociais se inserem no universo consensual, onde "Tudo o que é dito ou feito ali, apenas confirma as crenças e as interpretações adquiridas, corrobora, mais do que contradiz, a tradição". Como tudo o que não é familiar incomoda, surge o processo de categorizar as coisas, pessoas e acontecimentos, com a finalidade de trazê-los para o ambiente familiar. Nomear é uma forma encontrada para retirar da abstração às coisas e colocá-las "na matriz de identidade da nossa cultura" (p. 66, grifo do autor).

$\mathrm{Na}$ formação das representações, Moscovici (2003) trabalha com dois termos: Ancoragem e Objetivação. A Ancoragem é o processo onde algo que é estranho, nãofamiliar, passa a ser confrontado com um paradigma existente na memória, mesmo que seja para garantir um pouco de coerência entre o que é desconhecido e o que já faz parte do universo das pessoas. Ancorar é nomear o que é novo. Apoiado numa réplica do modelo familiar, os indivíduos podem comunicar e representar o não-usual. Em síntese, "pela classificação do que é inclassificável, pelo fato de se dar um nome ao que não tinha nome, nós somos capazes de imaginá-lo, de representá-lo” (MOSCOVICI, 2003, p. 62).

Quanto à Objetivação, é o processo de contextualizar as ideias abstratas. É a fase em que a palavra transforma-se em coisa, ou seja, a ideia ganha uma qualidade icônica, transformando-se em imagem. Nesse momento o invisível torna-se visível em imagens na mente dos indivíduos. O não-familiar deixa de ser ameaçador e passa a ser objeto familiar. Assim a representação passa a ser aceita e difundida, constituindo um núcleo central que irá permanecer "intacto" até que uma nova representação surja ou que o modifique. 
Moscovici (2003) dinamiza o conceito anterior e estático de representações coletivas de Durkheim ${ }^{1}$ transformando-as em processo, vendo-as como algo que muda conforme os contextos sociais, pois em qualquer cultura existem pontos de tensão e é ao redor desses pontos que novas representações surgem. Outro ponto importante destacado pelo autor é que enquanto Durkheim trata as representações como conceito, ele as aborda enquanto fenômenos que merecem ser explicados e daí a opção de uso do termo "social".

\section{O OLHAR DO RESIDENTE E AS REPRESENTAÇÕES SOCIAIS DO ESPAÇO URBANO TURÍSTICO}

Transitando de uma visão mais geral para uma visão mais restrita do espaço urbano turístico, a análise da representação social pode auxiliar no entendimento de quais elementos do espaço urbano turístico são representativos para os residentes, bem como evidenciar as significações inseridas na imagem cristalizada, revelando as informações, as crenças, os valores dos moradores em relação à atividade turística.

Vinculado a esse aspecto Kossoy (1999) discorre que as fotografias possuem realidades. A primeira realidade fotográfica compreende ao passado da foto e está ligada à realidade interior, ou seja, invisível, inacessível fisicamente. Já a segunda realidade, é o "produto" da primeira. É a representação de um instante dentro de um espaço imutável e está ligada a realidade exterior. Trata-se do conjunto de significados que independe das condições em que foi produzida a foto, constituindo o objeto de análise desse estudo.

Sendo a fotografia uma transposição de realidades e dimensões, pode-se afirmar que na primeira realidade está contida a dimensão da vida e na segunda realidade a dimensão da imagem (representação). A dimensão da vida é o que faz o indivíduo refletir sobre como os seres humanos enxergam a realidade e a materializam em objetos carregados de significados (fotografias). A partir desses esclarecimentos, inicia-se a análise das fotos a partir dos elementos do espaço urbano turístico que os residentes

\footnotetext{
${ }^{1}$ Émile Durkheim (1858-1917) é considerado um importante cientista social e suas obras integram o grupo de teorias da sociologia. Seus estudos ressaltam a interação social entre os indivíduos que integram uma coletividade: a sociedade. Para esse teórico, as representações coletivas se impõem sobre os indivíduos. Elas são formadas coletivamente e constituem o arcabouço cultural de uma sociedade. Já Moscovici (2003) acredita que as representações são geradas pelos atores sociais.
} 
mais gostam, ou seja: a Catedral de São Sebastião, o Instituto Nossa Senhora da Piedade, o Bar Vesúvio, o Rio Acuípe, a Baía do Pontal e a Praia do Sul.

\subsection{ANÁLISE DOS ELEMENTOS DO ESPAÇO URBANO TURÍSTICO QUE OS RESIDENTES GOSTAM}

$\mathrm{Na}$ análise dos equipamentos do espaço urbano turístico, especialmente os categorizados por Boullón (2002), considera-se relevante lembrar os componentes básicos que compõem a paisagem urbana descritos por Castrogiovanni (2001), pois os marcos, os roteiros, as bordas, os bairros, os setores e os logradouros revelam a natureza modificada pelo homem com finalidades de diversas ordens e carregadas de grandes simbologias.

A Catedral de São Sebastião (fotos 1 e 2) começou a ser edificada em 1931 e foi inaugurada em 1967, levando mais de 30 anos para ser construída (HEINE, 2004). Sua estrutura se destaca pelo tamanho. A abóboda principal chega a medir 48 metros de altura. Sua estrutura, fruto desse processo histórico e social, está representada através das formas, funções e identidade que se cria com a comunidade local. Trata-se de um marco imponente e, por isso, não passa despercebida aos registros dos residentes.

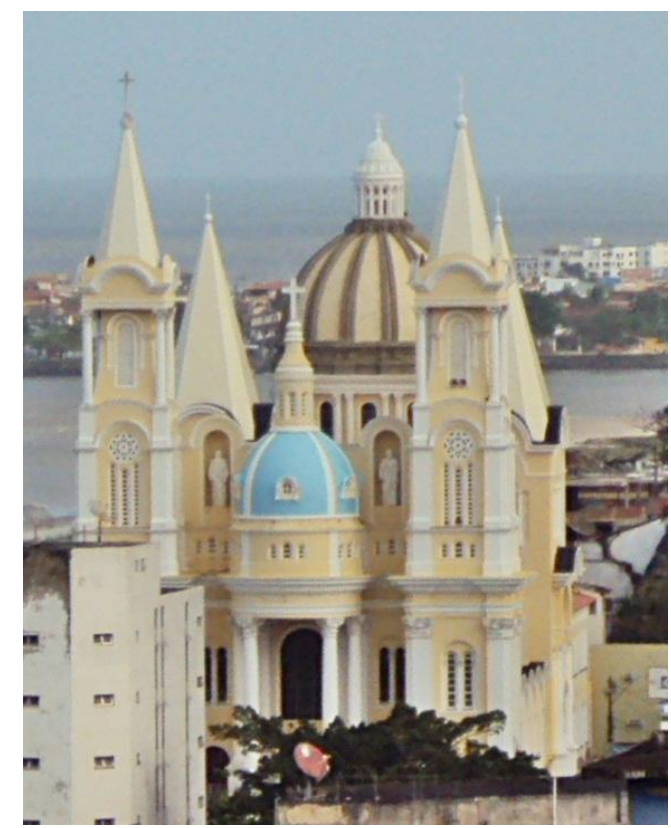

FOTO 1 - CATEDRAL DE SÃO SEBASTIÃO. Categoria de Representação Social: Crença e Valor. Variável: Marco. FONTE: RESIDENTE 1.

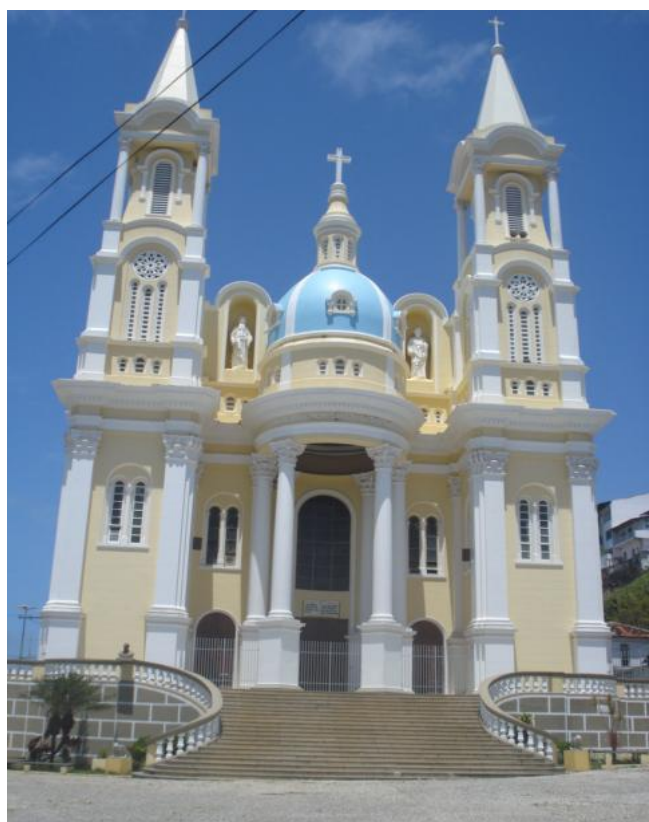

FOTO 2 - CATEDRAL DE SÃO SEBASTIÃO. Categoria de Representação Social: Crença e Valor. Variável: Marco. FONTE: RESIDENTE 2. 
Do ponto de vista das formas expressas na arquitetura, a catedral é constituída de formas retilíneas, principalmente com direções verticais, o que evidencia magnitude. De modo semelhante, formas cíclicas aproximam-se da perfeição buscada em diversos aspectos dentro da religião. Contudo, como apenas esses aspectos visíveis não devem ser considerados, uma vez que eles não dão conta por si só da autonomia turística do lugar, deve-se atentar também para função desempenhada por esse marco junto à sociedade.

Nesse sentido, é importante ressaltar que a Catedral de São Sebastião não se trata apenas de um marco fixo, mas de um elemento com instâncias móveis que dão vida ao seu espaço. A igreja, que está localizada na área central da cidade, além de servir como espaço de profissão de fé dos residentes, uma vez que cerimônias religiosas são realizadas no local, também agrega a função de atrativo turístico.

Assim, percebe-se que valores religiosos e crença estão diretamente ligados a representação desse marco no espaço urbano turístico de Ilhéus, refletindo parte da identidade do seu povo.

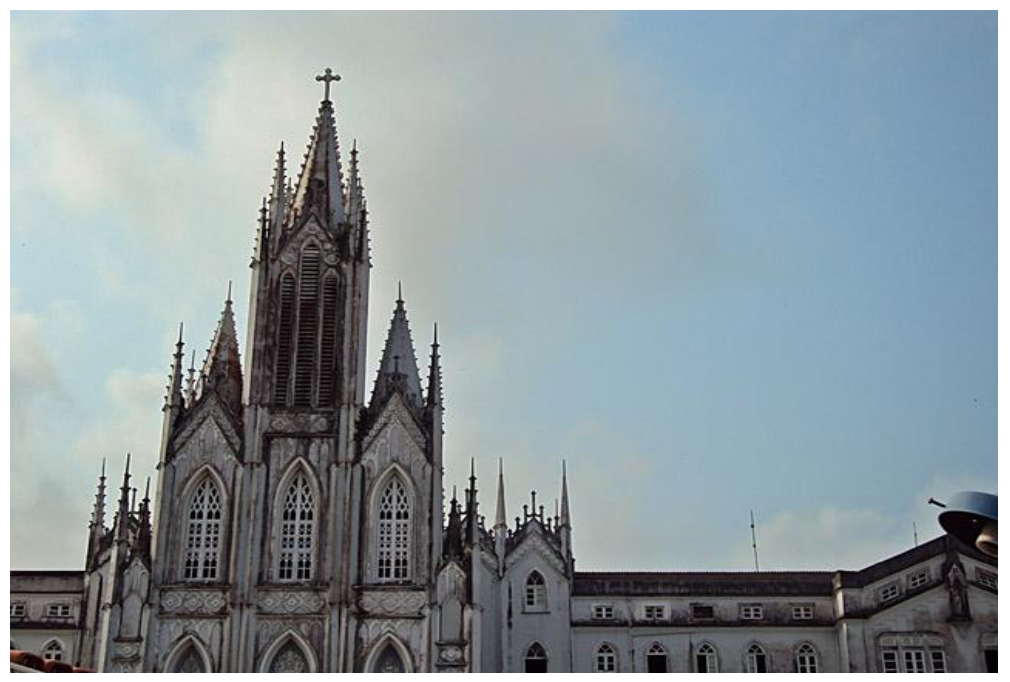

FOTO 3 - INSTITUTO NOSSA SENHORA DA PIEDADE.

Categoria de Representação Social: Crença e Valor. Variável: Marco.

FONTE: RESIDENTE 1.

O marco da foto 3 acima trata-se do Instituto Nossa Senhora da Piedade. Em 1916 as Freiras Ursulinas fundaram o Convento da Piedade, comandadas pela Madre Thaís do Sagrado Coração Paillart, Provincial da Ordem no Brasil (HEINE, 2004). As formas imponentes na arquitetura evidenciam estruturas das organizações sociais do início do século. Contudo, sua função foi mudando a partir do processo das ações que visam atender as novas gerações, implicando em novos usos do patrimônio, como por 
exemplo, o uso para fins educacionais. Isso significa dizer que os residentes vivenciam e mudam as representações e funções do espaço urbano empiricamente. Por isso, além de representar crença, representa também novos valores educacionais.

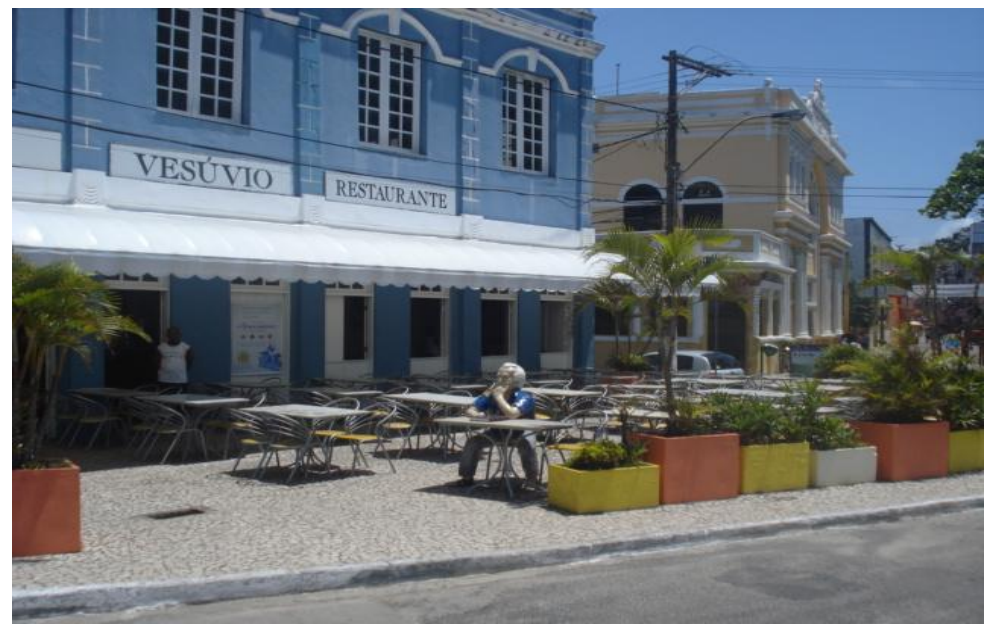

FOTO 4 - BAR VESÚVIO.

Categoria de Representação Social: Estereótipo e Valor. Variável: Marco, Roteiro e Setor. FONTE: RESIDENTE 2.

A foto 4 evidencia o Bar Vesúvio, que ficou famoso após ser relatado no romance "Gabriela, Cravo e Canela" de Jorge Amado, publicado em 1958. No mesmo ambiente, é possível notar, também, a estátua de Jorge Amado sentado à mesa. O bar constitui-se em um marco com grande função turística, estando presente no setor do Centro Histórico de Ilhéus.

A partir do pressuposto de Cruz (2003, p. 10), quando afirma que as "paisagens turísticas nada mais são, também, do que invenções, que criações culturais", nota-se que a construção simbólica em torno da sociedade local, retratada nos romances de Jorge Amado, constitui-se em um estereótipo, uma vez que elege determinados elementos para serem narrados. As relações de estereótipos estão associadas a questões identitárias, que, por sua vez, estão ligadas às representações sociais, permeando o universo comum e sendo absorvidas pelos seus residentes. Esse estereótipo pode ser percebido, por exemplo, quando o imaginário criado através da literatura dá mote ao slogan "Ilhéus, cidade romance do Brasil" ou "Carnaval de Ilhéus: Terra do Jorge, Amado por nós", slogan do carnaval municipal em 2011.

Partindo para análise dos elementos naturais, nota-se que as águas têm uma representação de valor muito grande para os residentes, uma vez que a cidade de Ilhéus 
é cercada e recortada pelas águas de rios e do mar. Assim, esses elementos aparecem nas fotografias 5 e 6 revelando significados subjetivos que podem ser mais bem analisados a partir do momento em que se têm consciência da geografia e da história do município.

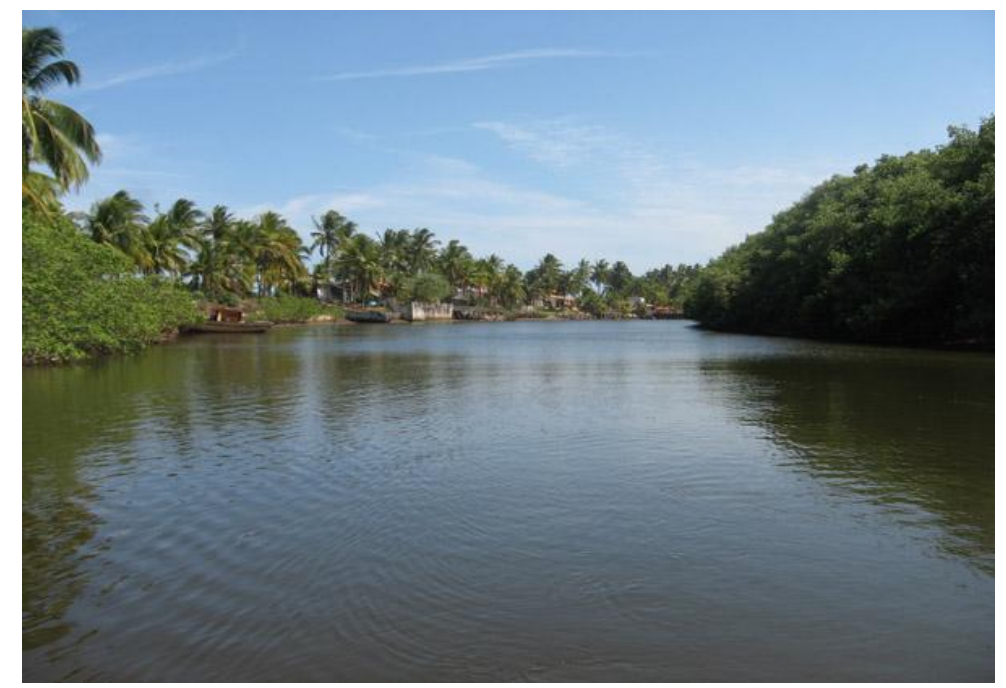

FOTO 5 - RIO ACUÍPE.

Categoria de Representação Social: Valor e Atitude. Variável: Bordas. FONTE: RESIDENTE 3.

A foto 5 acima possui representações de atitudes do homem em relação a natureza, considerando que os rios possibilitam benefícios à humanidade tais como: alimento, manutenção da biodiversidade e equilíbrio do ambiente. Também há uma atribuição de valor às fronteiras demarcadas pelas bordas entre o ambiente aquático e o terrestre, evidenciando a riqueza natural da cidade e sua vocação, enquanto atrativo, viabiliza o lazer para comunidade e visitantes.

Na perspectiva da geografia, a foto 6 mostra a Baía do Pontal, formada a partir do encontro do Oceano Atlântico com a foz dos rios Cachoeira, Santana e Fundão, representando o contato entre as bordas aquáticas e, também, terrestres. Nesse local, ocorrem importantes interações e trocas entre o homem e a natureza. Na perspectiva histórica, Ilhéus foi povoada primeiramente nas proximidades dos rios e do mar, revelando a dinâmica das ocupações territoriais e das atividades produtivas que ali se estabeleciam e se estabelecem. Os barcos ancorados mostram a simplicidade da pescaria desenvolvida pelos residentes, que possuem grande função dentro do contexto cultural e econômico de Ilhéus. 


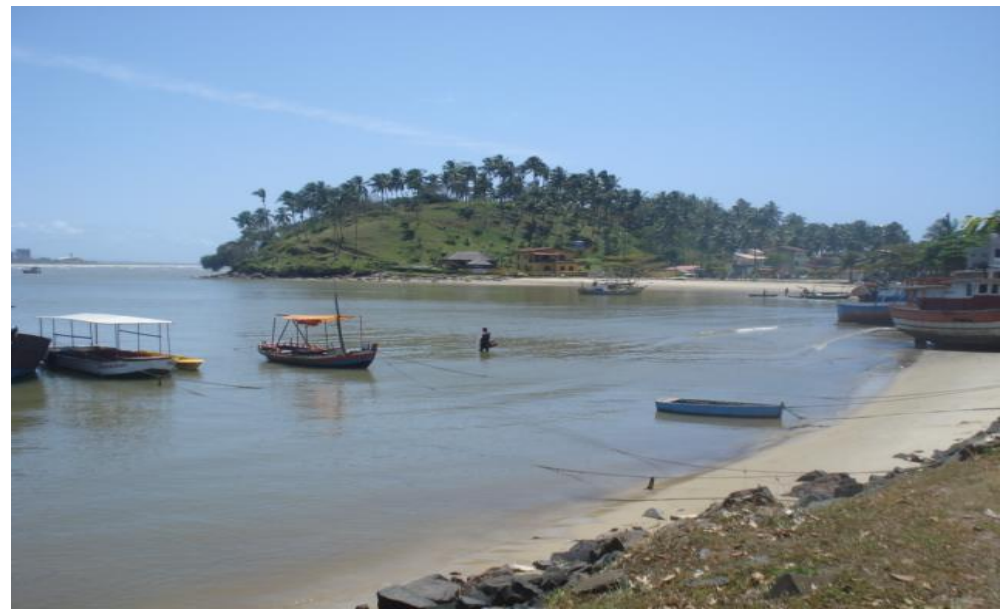

FOTO 6 - BAÍA DO PONTAL.

Categoria de Representação Social: Valor e Atitude. Variável: Bordas. FONTE: RESIDENTE 4.

As fotos 7 e 8 retratam bordas e logradouros, sendo também roteiros para visitação às belezas naturais das praias do litoral sul, constituindo-se num importante atrativo turístico de Ilhéus, que explora o turismo de sol e praia. Contudo, para os residentes, esses elementos do espaço urbano não se configuram apenas como atrativo turístico, possuindo outros significados, representando valores e atitudes.

A divisão que existe entre as Praias do Norte e as Praias do Sul possui uma representação mais ampla do que a simples posição geográfica. Em algumas praias do litoral norte é possível ver a poluição com maior incidência e a falta de infraestrutura para o lazer. Em grande parte, a falta de infraestrutura está ligada ao processo de assoreamento provocado pelo molhe do Porto do Malhado. Nesse trecho observa-se também a ausência de saneamento básico, orla exposta e áreas subutilizadas, conforme apresenta o Projeto Orla (2007). Já as praias do litoral sul são mais freqüentadas, uma vez que as águas são mais apropriadas para o banho e o local tem melhor infraestrutura. Assim, os valores sociais e ambientais constituem-se em fontes importantes de representação para a escolha de determinados equipamentos. 


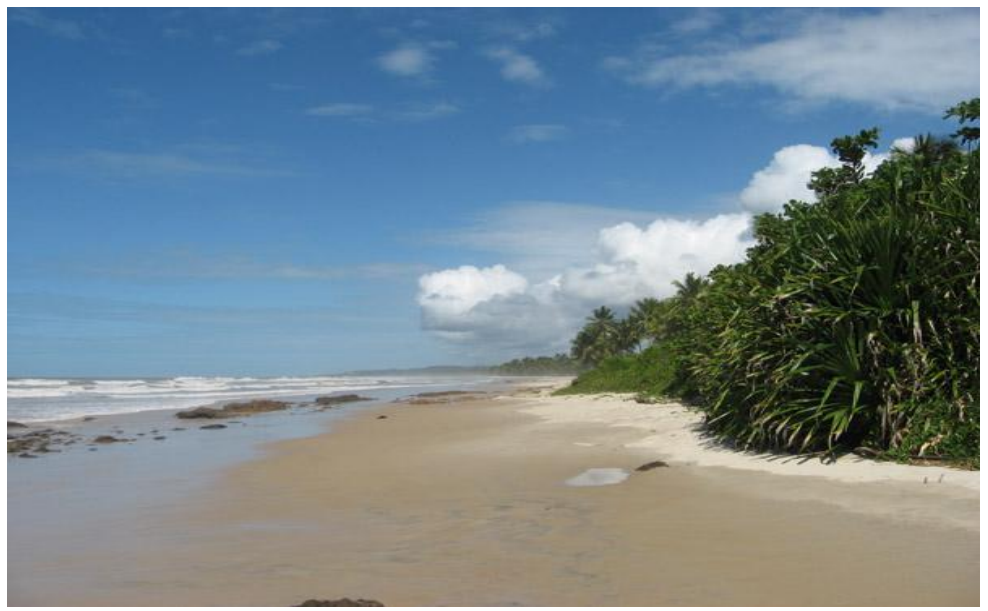

FOTO 7 - PRAIA DO SUL.

Categoria de Representação Social: Valor e Atitude. Variável: Bordas. FONTE: RESIDENTE 3.

Nas fotografias 7 e 8 podem-se verificar ainda as representações de atitude: tranquilidade e agitação. A foto 7 retrata a Praia do Sul, um lugar onde se preserva o contato e a contemplação com o ambiente natural, sendo um refúgio de locais onde ocorrem muitos ruídos provocados pela maior circulação de pessoas. Já a foto 8 retrata uma cabana de praia localizada em um trecho da Praia do Sul, apresentando um equipamento modificado pela ação humana, caracterizado por possuir uma infraestrutura voltada para a prestação de serviços aos turistas e residentes. Esses ambientes constituem-se num importante espaço de trocas culturais.

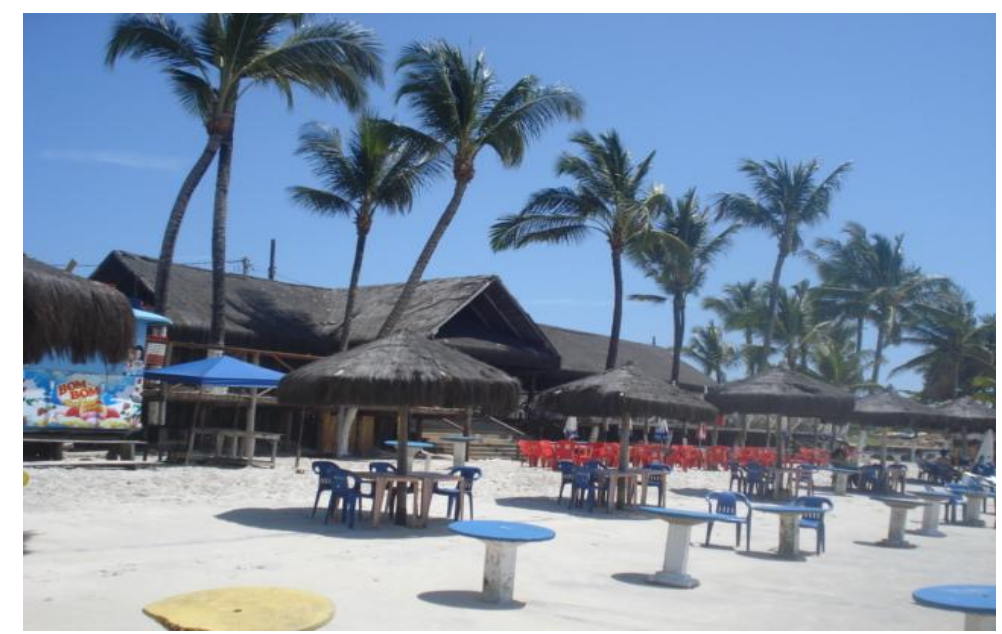

FOTO 8 - CABANA DE PRAIA NA PRAIA DO SUL.

Categoria de Representação Social: Valor e Atitude. Variável: Bordas, Roteiro, Logradouro. FONTE: RESIDENTE 4. 


\subsection{ANÁLISE DOS ELEMENTOS DO ESPAÇO URBANO TURÍSTICO QUE OS RESIDENTES NÃO GOSTAM}

O espaço urbano é fruto do fluxo de pessoas que o mantém vivo e dinâmico. Contudo, o reflexo do comportamento humano nesse ambiente nem sempre tem efeito positivo. Assim, parte-se para análise das fotografias que corresponderam aos elementos negativos presentes no espaço urbano turístico de Ilhéus segundo julgamento dos residentes consultados. Os elementos fotografados foram os seguintes: Praia do Sul, borda do Rio Almada, orla da Praia dos Milionários, vista do Porto do Malhado, área de assoreamento na Avenida Soares Lopes e comércio na área central de Ilhéus.

Nesse processo de análise, se teve como constatar que um mesmo local pode ter significados diferentes. A Praia do Sul, ambiente abaixo retratado (foto 9) e que foi concebido como local propício à interação social e cultural anteriormente (foto 8), no atual contexto, é reflexo da desordem, representando valores e atitudes negativas imbricadas do espaço urbano turístico.

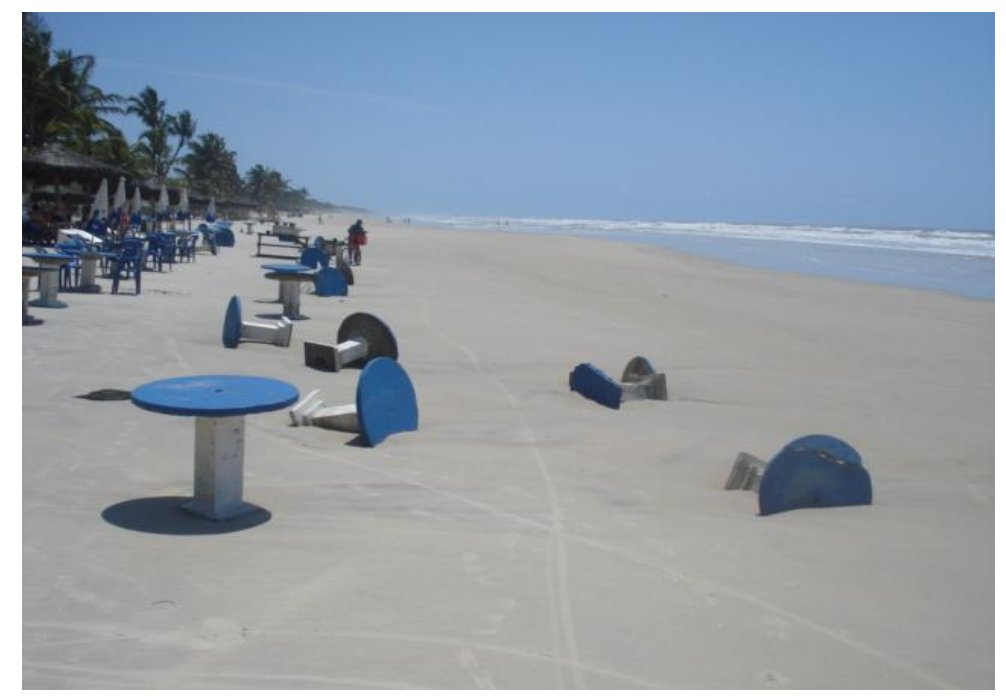

FOTO 9 - PRAIA DO SUL.

Categoria de Representação Social: Valor e Atitude. Variável: Bordas. FONTE: RESIDENTE 4.

A borda da faixa da praia é o cenário do conflito existente entre a ação da natureza e do homem. É o espaço natural sendo invadido pelas edificações que, por sua vez, são confrontadas pela natureza. Portanto, num mesmo local notam-se representações diferentes e dicotômicas: a representação do caos, do conflito, da degradação e a representação do lazer, do ócio. 
Outro ponto importante a ser destacado é que, mesmo sendo produto de diferentes olhares e perspectivas dos residentes, alguns elementos do espaço urbano turístico tornam-se latentes nas representações, como é o caso das fotografias 10, $11 \mathrm{e}$ 12, onde se encontram incrustados valores e atitudes. As fotos retratam entulhos, lixo, evidenciando os valores que representam o sentimento de reprovação às atitudes de degradação do espaço. Pode-se dizer que tal representação está ligada a valores educacionais e ambientais dos residentes que as fotografaram, já que tratam de reprovação de determinada ação.

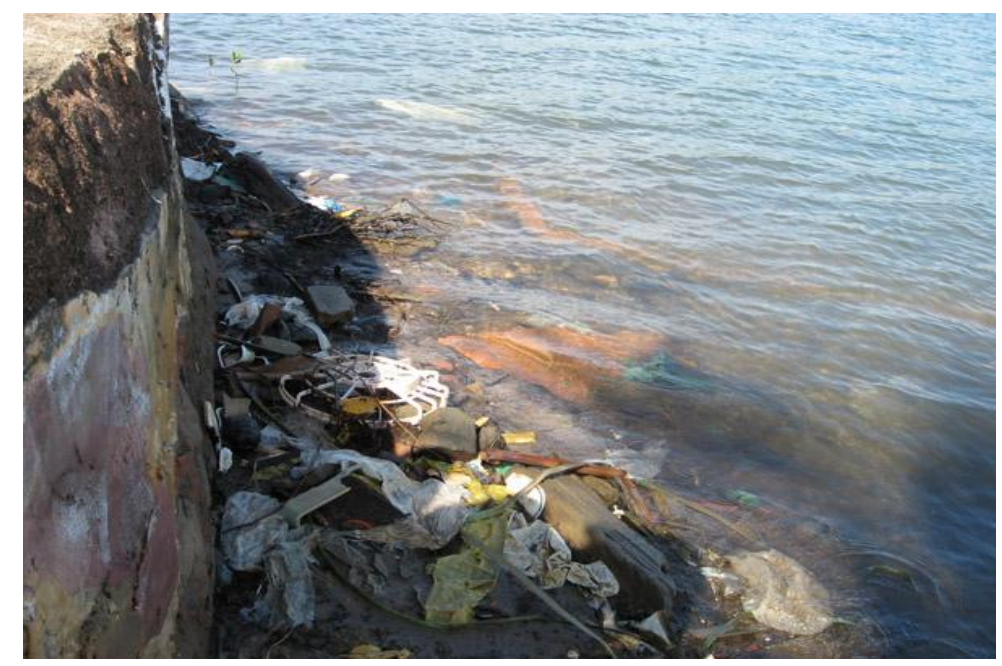

FOTO 10 - BORDA DO RIO ALMADA.

Categoria de Representação Social: Valor e Atitude. Variável: Bordas. FONTE: RESIDENTE 3.

Outra característica peculiar desse tipo de ação, é que o lixo sempre está nas bordas, ficando às margens dos logradouros e dos roteiros turísticos. Estão à margem justamente por se tratar de objetos que supostamente não servem mais, não têm utilidade e, por isso mesmo, são rejeitados. Analisando alguns elementos da composição fotográfica, percebem-se alguns resíduos de bens de consumo duráveis, como, por exemplo, parte de um ventilador (foto 10), evidenciando que trata-se de lixo residencial, supostamente descartado pelo próprio habitante da cidade.

Atentando para as fotos 11 e 12, nota-se que ambas tratam de um mesmo local: a orla da Praia dos Milionários. Contudo, a tomada de ângulo dos diferentes residentes denota a diferença do olhar e da representação sobre aquele espaço, mostrando como alguns elementos se tornam mais representativos que outros. Isso caracteriza a visão de Castrogiovanni (2001, p. 27) quando afirma que o objeto que o indivíduo vê se baseia 
na forma, mas o modo de percepção afeta aquilo que ele observa, isso ocorre porque o “organismo humano é extremamente adaptável e flexível a partir do seu processo cultural, portanto grupos diferentes podem representar imagens diferentes da mesma forma observada".

Enquanto o residente que focou a foto 11 se ateve apenas em fotografar o lixo acumulado, o residente da foto 12, além de mostrar o lixo aglomerado, demonstrou preocupação em mostrar que as lixeiras estavam vazias, denotando a atitude, a representação do descaso. É importante ampliar essa discussão, pois geralmente a palavra "descaso" é associada aos discursos contra o poder público, principalmente quando se trata de infraestrutura e neste aspecto, sem intenção de isentar o poder público da sua função e obrigação social, a foto 12 evidencia que essa atitude não trata apenas de um problema de gestão pública, mas sim do comportamento dos habitantes e turistas, uma vez que evidencia valores e atitudes educacionais, representados pela poluição sanitária e visual e que impossibilita o acesso à Praia dos Milionários.

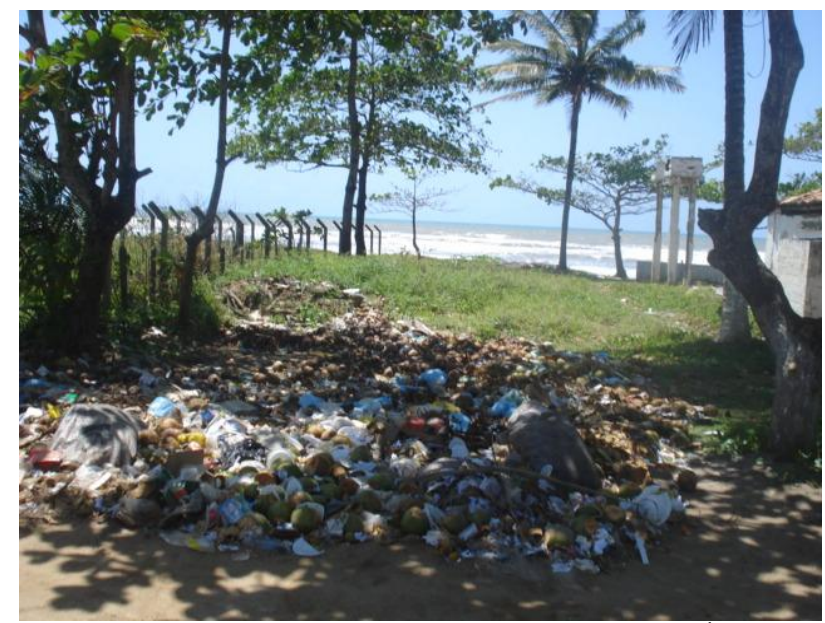

FOTO 11 - ORLA DA PRAIA DOS MILIONÁRIOS. Categoria de Representação Social: Valor e Atitude. Variável: Bordas. FONTE: RESIDENTE 2.

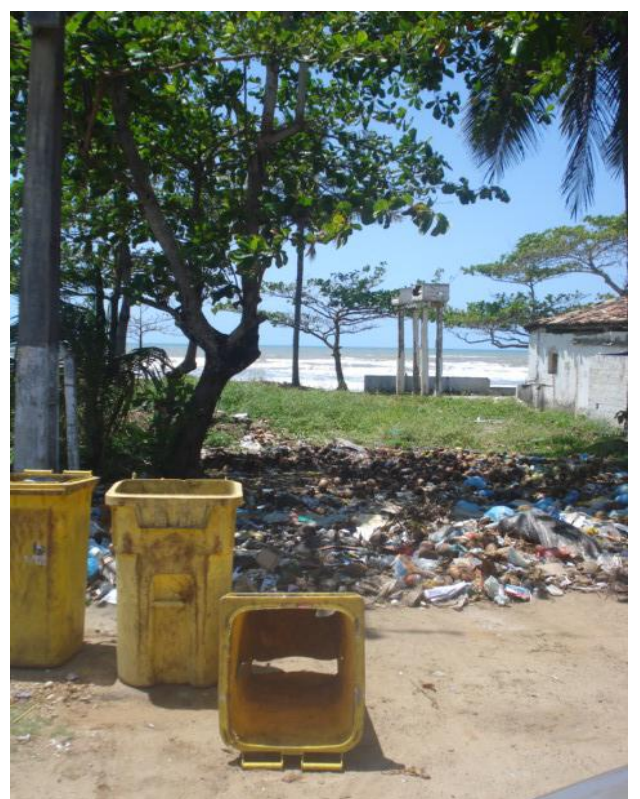

FOTO 12 - ORLA DA PRAIA DOS MILIONÁRIOS. Categoria de Representação Social: Valor e Atitude. Variável: Bordas. FONTE: RESIDENTE 4.

Já a fotografia 13 mostra as bordas e claramente as fronteiras dos elementos: porto, mar e pedras. Esse conjunto de elementos denota sentimento de preocupação e de alerta. A imagem tem em si diversos elementos que permitem uma leitura ampla. Ao fundo da fotografia tem-se uma infraestrutura construída com grandes 
empreendimentos. Trata-se do Porto do Malhado, onde se concentram grandes investimentos em tecnologia, gestão, controle e escoamento da produção. No extremo oposto e em primeiro plano fotográfico, tem-se os urubus.

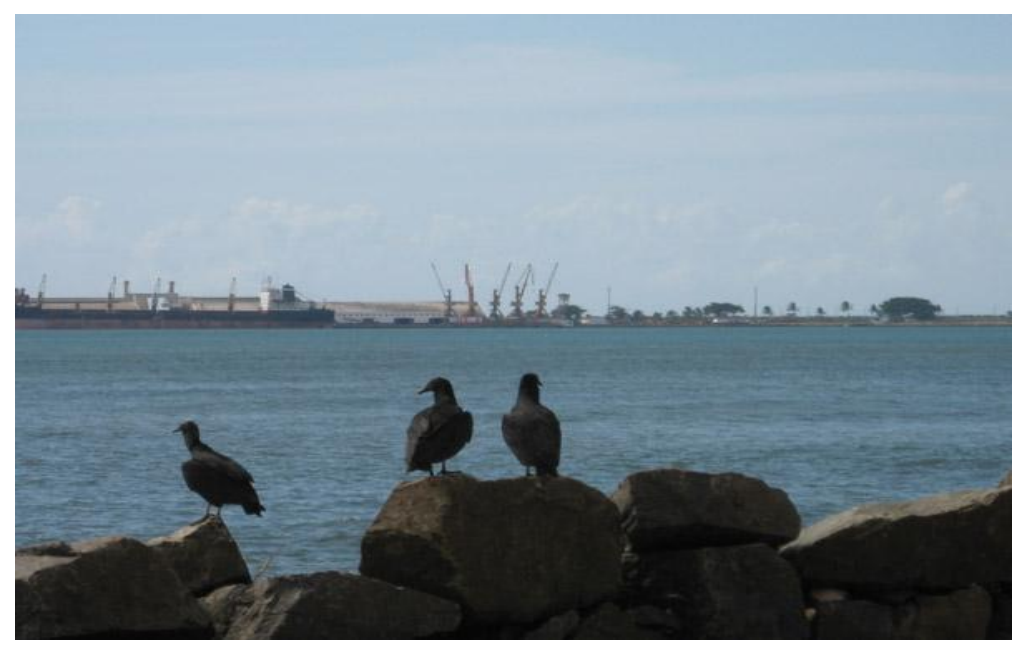

FOTO 13 - PORTO DO MALHADO.

Categoria de Representação Social: Valor e Atitude. Variável: Bordas. FONTE: RESIDENTE 3.

Os urubus, no sentido semiótico, servem como signos e indícios de que pode haver resíduos de lixo acumulados de maneira inadequada, apesar de tais elementos não apresentarem-se explicitamente na foto. No meio da dicotomia entre a eficiência/deficiência, tecnologia/atraso, boa gestão/má gestão, escoamento de produção/acúmulo de resíduos, está o mar. O mar destaca-se pela cor viva, pela imensidão, mas que parece vulnerável diante das ações nocivas humanas. Valores e atitudes estão implícitos e explícitos nessa representação.

O processo de assoreamento causado pela construção do Porto do Malhado é outro elemento apontado negativamente pelos residentes. Trata-se de atitudes humanas que, em virtude do progresso em determinada área, fez o mar recuar, deixando exposta a orla da praia. 


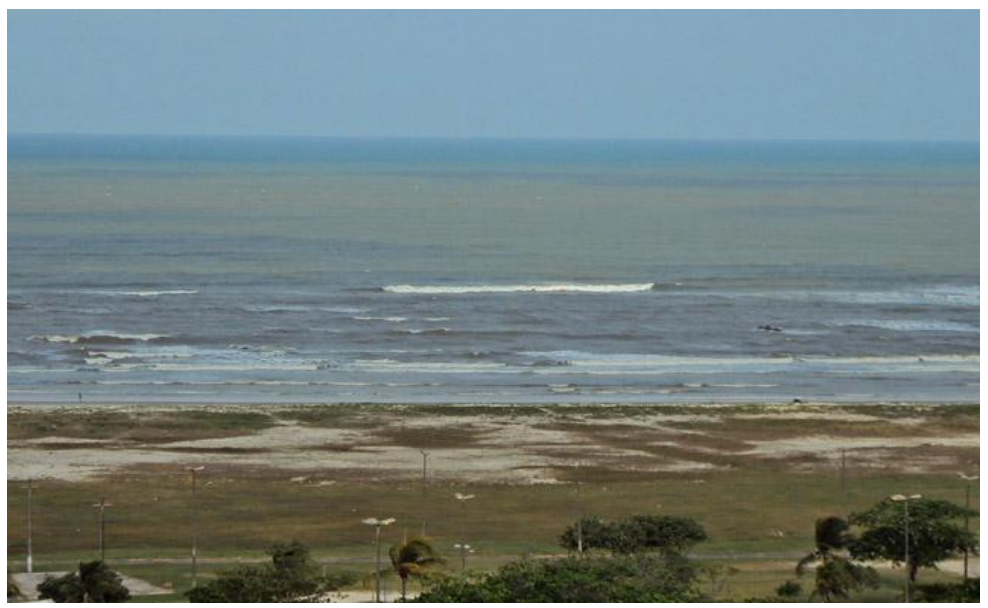

FOTO 14 - ÁREA DE ASSOREAMENTO NA AVENIDA SOARES LOPES.

Categoria de Representação Social: Valor e Atitude. Variável: Bordas. FONTE: RESIDENTE 1.

À fotografia acima se soma a foto abaixo, permitindo uma visão mais vasta do processo de assoreamento. A foto retrata a Avenida Soares Lopes, considerada um dos cartões postais de Ilhéus, que se apresenta como borda da cidade ao se limitar com a orla e com o mar. Também pode ser considerada como logradouro, uma vez que é espaço de circulação de pessoas. E ainda, na mesma perspectiva, ser classificada enquanto roteiro, servindo como trajeto que dá acesso a diversos elementos turísticos da cidade, inclusive ao Centro Histórico.

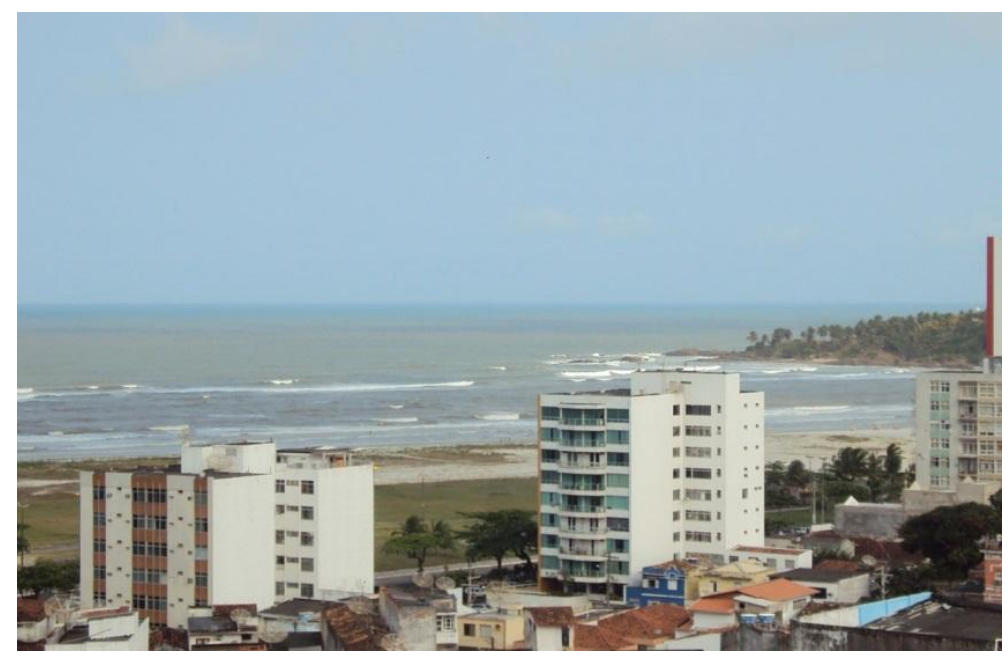

FOTO 15 - ÁREA DE ASSOREAMENTO NA AVENIDA SOARES LOPES EM PLANO GERAL. Categoria de Representação Social: Valor e Atitude. Variável: Bordas, Logradouro e Roteiro. FONTE: RESIDENTE 1.

O trecho da Avenida Soares Lopes mostra a representação do abandono, da falta de planejamento e de infraestrutura adequada às necessidades sociais tanto dos 
residentes quanto dos turistas. Pode-se notar que ambas as fotografias (14 e 15) foram registradas pelo mesmo residente, o que demonstra que essa é uma representação forte e latente no seu contexto, descrevendo também valores e sentimentos em relação ao seu espaço.

De acordo com o Projeto Orla (2007), fruto da gestão integrada entre poder público municipal, estadual e federal, a área de assoreamento está susceptível ao uso e à ocupação inadequados e carece de infraestrutura que atenda ao bem-estar dos residentes e turistas. Dentro do contexto histórico, social, político, cultural e econômico, a Avenida Soares Lopes representa um importante ponto de referência para os cidadãos de Ilhéus, uma vez que nela acontecem grandes eventos de ordem prática e simbólica.

Vinculada a essa questão verifica-se que conforme Gastal (2001) a cidade surge em contingência ao espaço privado, sendo o espaço público onde se refletem as necessidades, sentimentos e atitudes coletivas. Na cidade as pessoas constroem e agem sobre estruturas para depois serem confrontadas por elas. Nesse contexto, aparecem as categorias de valores e atitudes tendo como representação a marginalidade, entendida aqui no seu contexto essencial: o indivíduo que está à margem da sociedade, excluído dos benefícios construídos coletivamente e dos direitos assegurados ao cidadão.

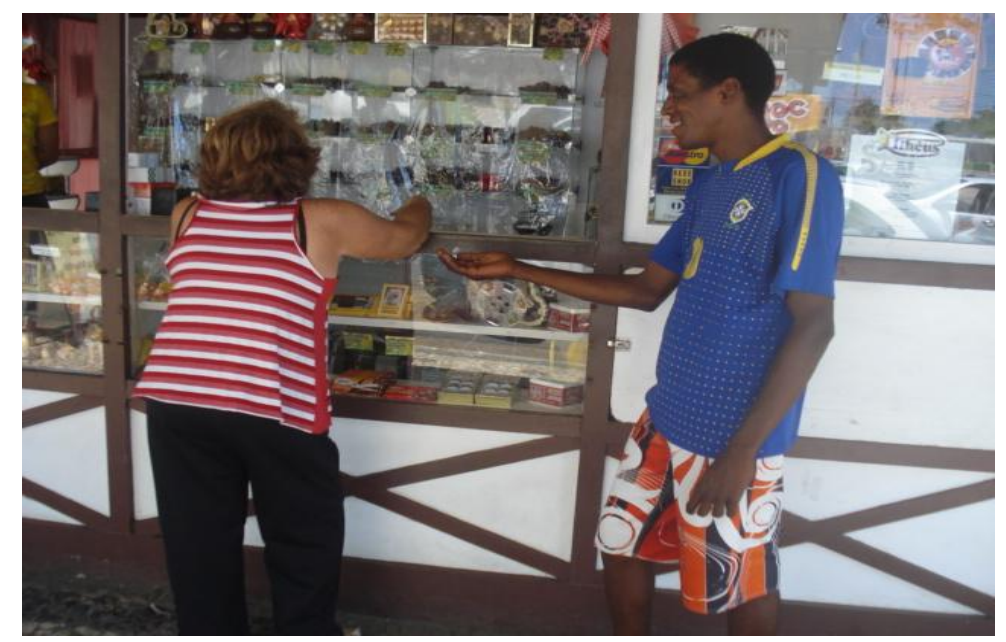

FOTO 16 - HOMEM PEDINDO ESMOLA NO COMÉRCIO, CENTRO DE ILHÉUS. Categoria de Representação Social: Valor, Atitude e Preconceito. Variável: Roteiro e Logradouro. FONTE: RESIDENTE 2.

A foto acima retrata o confronto de realidades nas estruturas sociais construídas. De acordo com o senso comum, o indivíduo que pede esmola é um elemento que incomoda e que não deve fazer parte desse ambiente turístico e social. $\mathrm{O}$ valor embutido na fotografia denota a falta de civilidade, bem como a degradação de valores morais e 
éticos. Para Castrogiovanni (2001, p. 24-25), a cidade é um produto social construído por classes, onde alguns "adquirem maior ascendência sobre a configuração do espaço urbano, em razão de terem maiores influências econômicas e políticas do que os outros”. Uma terceira categoria de análise se gesta nesse ambiente: o preconceito.

Ao levar em consideração apenas o momento cristalizado na imagem e a análise dos signos presentes, é possível perceber que o ângulo escolhido pelo residente para fotografar, reflete, em parte, o preconceito. Tomando o perfil do homem que pede esmola, evidencia-se a marginalidade. Registrando as costas da pessoa que realiza compras, tem-se o avesso, ou seja, a representação da pessoa com condições de comprar e que, portanto, pode usufruir dos bens gerados na cidade.

\section{CONSIDERAÇÕES FINAIS}

Após a análise das fotografias, se considera que se teve como constatar que os marcos e as bordas são os elementos do espaço urbano turístico que os residentes de Ilhéus envolvidos nesta abordagem mais gostam. Nos marcos estão impregnadas as representações sociais de crença e valor. Nas bordas, relacionadas com os atrativos naturais, estão as representações de atitude e valor. A representação do estereótipo está associada ao imaginário sobre Ilhéus criado e difundido nas obras de Jorge Amado.

Quanto aos elementos do espaço urbano turístico que os residentes envolvidos não gostam, aparecem as bordas de ambientes naturais, com grande representação social de valor e atitude em relação à degradação do patrimônio natural. O preconceito aparece evidenciando problemas de ordem econômica e social.

O núcleo central das representações sociais dos residentes abordados foi o de valores sociais e ambientais, crença e atitude. Os valores e atitudes ambientais podem ser explicados pela formação geográfica da cidade que coloca os seus moradores em contato direto com inúmeros recursos naturais: rios, mar, morros, matas, mangues. A crença ligada a questões religiosas. Os marcos representam a arquitetura de templos religiosos construídos sob influência da Igreja Católica durante o período de colonização e cultivo da lavoura cacaueira.

Os diferentes significados atribuídos ao espaço urbano turístico mostram como as representações sociais mudam, já que elas se transformam frente às circunstâncias 
temporais e espaciais. As estruturas construídas pelos indivíduos para atender determinadas necessidades, passam a confrontar outros indivíduos, que lhes atribuem outros significados a partir das suas vivências. Isso ficou constatado quando um mesmo espaço geográfico pôde ser representado distintamente, evidenciando as diversas formas de olhar e fotografar um mesmo elemento.

Percebe-se que qualquer processo de planejamento turístico deve levar em consideração as representações já existentes no espaço urbano, principalmente para os residentes. Quando não há uma análise das representações sociais dos elementos que compõem o ambiente urbano, a tendência é agregar outras representações, com as quais os residentes podem não estar familiarizados, trazendo a tona uma série de conflitos sociais, culturais, políticos, econômicos e religiosos. É nesse sentido que se podem entender os conflitos que se estabelecem entre turistas e moradores de determinadas localidades.

Considera-se que o estudo das representações sociais do espaço urbano turístico pode ser um instrumento a ser utilizado para planejar e conduzir de forma mais coerente e equilibrada a gestão do patrimônio material e imaterial de Ilhéus, bem como preservar os valores sociais, culturais e ambientais existentes. A efetivação de planos e projetos que congreguem interesses e benefícios tanto para os residentes quanto para os visitantes, possibilita um alcance maior de objetivos que conduzam a melhoria, valorização e gestão dos recursos presentes nos espaços urbanos, potencializando a qualidade da cidade como espaço construído pelas relações sociais em meio a atividades habituais e turísticas.

\section{REFERÊNCIAS}

BOMFIM, N. R. Patrimônio, turismo e planejamento: formatação de produtos. In: CAMARGO, P. de; CRUZ, G. da. (Orgs.). Turismo cultural: estratégias, sustentabilidade e tendências. Ilhéus, BA: Editus, 2009.

BOULLÓN, R. C. Planejamento do espaço turístico. Bauru, SP: EDUSC, 2002.

CASTROGIOVANNI, A. C. Turismo e ordenação no espaço urbano. In: BARRETTO FILHO, A.; CASTROGIOVAnNI, A. C. (Org.). 2. ed. Turismo urbano. São Paulo: Contexto, 2001.

CRUZ, R. de C. A. da. Introdução à geografia do turismo. São Paulo: Roca, 2003. 
GASTAL, S. O produto cidade: caminhos de cultura, caminhos de turismo. In: BARRETTO FILHO, A.; CASTROGIOVANNI, A. C. (Org.). 2. ed. Turismo urbano. São Paulo: Contexto, 2001.

HEINE, M. L. Projeto: Vamos conhecer nosso patrimônio. Ilhéus, BA. 2004.

KOSSOY, B. Realidades e ficções na trama fotográfica. Cotia: Ateliê Ed., 1999.

MOSCOVICI, S. Representações Sociais: investigação em psicologia social. Petrópolis, RJ: Ed. Vozes, 2003.

PROJETO ORLA. Plano de Gestão Integrada da Orla Marítima. Ilhéus, BA, 2007.

SIVIERO, A. P. Os elementos do espaço turístico urbano no processo de planejamento: reflexões teóricas e articulações. RA'E GA, Curitiba, n. 11, p. 51-59, 2006. Editora UFPR.

Recebido em: 28-03-2011.

Aprovado em: 28-04-2011. 